\title{
共建与区域产学研联合办学背景下应用化学专业建设与成效
}

霍冀川 $1,2,3,{ }^{*}$, 雷永林 ${ }^{1,3}$, 叶旭 ${ }^{1}$, 雷洪 ${ }^{1}$, 李鸿波 ${ }^{1,3}$, 钟国清 ${ }^{1}$, 张亚萍 ${ }^{1,3,4}$, 张廷红 ${ }^{1}$, 彭汝芳 ${ }^{3}$, 林晓艳 ${ }^{1,4}$

1 西南科技大学材料科学与工程学院, 四川绵阳 621010

2 西南科技大学分析测试中心, 四川绵阳 621010

3 环境友好能源材料国家重点实验室, 四川绵阳 621010

4 生物质材料教育部工程研究中心, 四川绵阳 621010

摘要: 针对地方高校学科、专业与课程建设各自为政, 难于提升人才培养质量的现象, 挖掘区域特色优势, 在共建 与区域产学研联合办学背景下, 对标 “双一流” 和 “新工科” 及 “双万计划”, 开展学科、专业与课程一体化建设, 构建基于导师加团队、平台、培养方案的科研教学协同三全育人生态体系, 建设应用化学国家一流专业, 培养复合 创新人才。

关键词: 应用化学; 三全育人; 学科、专业与课程一体化; 共建与区域产学研联合办学

中图分类号: G64; O6

\section{Development and Effectiveness of Applied Chemistry Specialty Construction under the Background of Co-construction and Regional Industry-University-Research Joint Education}

\author{
Jichuan Huo ${ }^{1,2,3,{ }^{*}}$, Yonglin Lei ${ }^{1,3}$, Xu Ye ${ }^{1}$, Hong Lei ${ }^{1}$, Hongbo Li ${ }^{1,3}$, Guoqing Zhong ${ }^{1}$, \\ Yaping Zhang ${ }^{1,3,4}$, Tinghong Zhang ${ }^{1}$, Rufang Peng ${ }^{3}$, Xiaoyan Lin ${ }^{1,4}$ \\ ${ }^{1}$ School of Materials Science and Engineering, Southwest University of Science and Technology, Mianyang 621010, \\ Sichuan Province, China. \\ ${ }^{2}$ Analytical and Testing Center, Southwest University of Science and Technology, Mianyang 621010, Sichuan Province, China. \\ ${ }^{3}$ State Key Laboratory of Environment-Friendly Energy Materials, Mianyang 621010, Sichuan Province, China. \\ ${ }^{4}$ Engineering Research Center of Biomass Materials, Ministry of Education, Mianyang 621010, Sichuan Province, China.
}

\begin{abstract}
The disciplines, majors, and courses are presently independent in most of the local colleges and universities, which makes it difficult to improve the quality of talent cultivation. In response to this phenomenon, the integrated construction of disciplines, majors and courses was carried out. A "Three All-round" scientific research and teaching collaboration education ecosystem based on mentors, teams, platforms, and training programs has been constructed, by tapping the advantages of regional characteristics and benchmarking "Double First Class", "Emerging Engineering Education" and "Double Ten Thousand Plan" under the background of co-construction and regional industry-university-research joint education. A national first-class major in applied chemistry has been established to cultivate compound innovative talents.
\end{abstract}


Key Words: Applied chemistry; Three all-round education; Integration of disciplines-majors-courses;

Co-construction and regional industry-university-research joint education

人才培养是专业建设的核心，专业特色是建设一流本科的基石，是高校优化专业结构、提高人 才培养质量、办出专业水平的重要措施。但由于历史原因, 地方高校在学科建设、专业建设、课程 建设、教材建设及教学模式改革方面往往分属于不同行政部门管理, 其统一性、关联性及协同性不 高 ${ }^{[1]}$ 。在资金有限的情况下, 二级学院如何从整体性和系统性出发, 实现专业、学科与课程一体化发 展, 成为各高校二级学院探讨的热点 ${ }^{[2]}$ 。

“共建与区域产学研联合办学” 是西南科技大学特色的办学模式 ${ }^{[3,4]}$, 其内涵是国家部委与省、 市共建, 科研院所和大型企业参与联合办学。通过整合、共享区域教育科技资源, 构建现代开放式 教育与科技合作交流平台, 增强高校人才培养、科学研究和服务社会的能力。西南科技大学材料科 学与工程学院, 在共建与区域产学研联合办学背景下, 对标 “双一流” 和 “新工科” 及 “双万计划”, 将化学学科、应用化学专业与相关课程进行一体化建设, 取得了较好的成效。

\section{1 学科、专业与课程一体化建设的发展历程}

2001年成立材料科学与工程学院, 学校管理重心下移, 实行 “以学院为管理重心” 的运行机制。 2002年在 “共建与区域产学研联合办学” 背景下, 与中国工程物理研究院化工材料研究所联合建成 应用化学硕士点, 2003年开始招收应用化学专业本科生, 2005年学院实行本科生人才培养导师制。 2006年实施本科生研究性学习为主体的研究生副导师制, 开展应用化学专业本科生与研究生教育衔 接, 建立化学科研创新基地, 设立科研项目, 探索科研教学协同育人, 与中国工程物理研究院化工材 料研究所和沾州北方化学工业有限公司联合开办应用化学(含能材料)专业方向。2007年在教育部、 财政部决定实施 “高等学校本科教学质量与教学改革工程” (简称质量工程)背景下, 学院探索学科、 专业与课程一体化建设。2012年以来, 学院开始对标 “双一流” “新工科” 及 “双万计划” , 构建了 导师加团队、平台、培养方案一体化的科教协同三全育人生态体系。2013年应用化学(含能材料)方向 成功培育为 “特种能源技术与工程” 国防学科新专业, 应用化学专业(仪器分析方向)成为创新人才培 养班, 另外举办了应用化学专业卓越工程师教育培养班。2014年, 应用化学(精细化工)方向发展成为 国家战略性新兴产业专业 “能源化学工程”。2020年应用化学成为四川省一流本科专业建设点, 特种 能源技术与工程成为四川省一流本科专业建设点, 2021年应用化学成为国家一流本科专业建设点。

\section{2 基于学科、专业与课程一体化的应用化学专业特色建设成效}

专业特色是指高校专业在长期的办学过程中形成和表现出来的, 与同类专业相比具有比较稳定 的、独特的风格或优势的特点。专业特色是专业生存和发展的关键因素, 是衡量其办学水平和人才 培养质量的重要标志。应用化学专业研究范围涵盖了整个化学领域, 并与多门学科相互渗透。任何 高校都不可能贪大求全, 而是必须结合区域特点、自身资源、专业背景等, 明确应用化学专业的特 色和发展方向。西南科技大学材料科学与工程学院结合绵阳科技城、西部大开发的区域特点, 确定 了专业的发展特色。

\section{1 紧密结合地方和区域经济建设与发展设置特色专业方向}

我校1993年招收第一届工业分析(硅酸盐工业分析)专科生, 2001年与绵阳经济技术高等专科学 校应用技术系的商品检验、环境检测、工业分析三个专科专业合并, 以应用化学专科专业招生。2003年 招收第一届应用化学本科生。应用化学的传统专业方向是工业分析, 且以硅酸盐工业分析为主。

学校所在地绵阳是被誉为 “西部硅谷” 的科学城, 其科研优势集中在电子工业和国防、军工产 业。其中中国工程物理研究院的智力资源密集, 储备了大量技术, 迫切需要军用技术向民用技术转 化。尤其是随着含能材料在民用领域的应用扩大, 以及环境保护对放射性污染的日益重视和要求的 
不断提高, 地方对含能材料和放射化学人才需求加大。绵阳地处西部, 是我国农业和生物质资源富 集地区, 发掘地方特色优势资源, 开展生物质资源高效利用技术研究, 加强生态保护与治理, 发展 环保产业, 必将拉动对生物质化学专业人员的需求。同时, 四川是矿产资源大省, 拥有大量建筑材 料制造业。随着我国西部大开发力度的加大, 建筑材料制造业的规模和产量已随之扩大, 这必将拉 动对化学建材和基于建材的工业分析专业方向的人才需求。

基于此, 学院结合专业实际情况和区域特点, 持续强化分析化学方向(硅酸盐工业分析)等传统 优势特色专业方向, 并在此基础上, 利用董事单位的优势资源, 发展放射化学方向及含能材料方向; 同时发展应用化学专业的精细化工新专业方向(化学建材、生物质化学衍生物) ${ }^{[5]}$ 。

\section{2 成功培育 “特种能源技术与工程” 国防特色专业}

为更好地服务于国防事业, 本专业在 2003 年第一届本科生招生时就开设了以核材料和含能材料 为特色的国防应用化学方向。2006年明确将精细化工(含能材料特色)方向调整为应用化学(含能材料) 方向。在董事单位的协助下, 应用化学(含能材料方向)建设取得显著成效。2007年, 该方向划归国防 科技学院以应用化学(含能材料)独立一本招生。2010年以后, 学院采取与中国工程物理研究院化工 材料研究所、国营泸州化工厂和四川雅化集团等单位联合共建的办学模式, 开展能源工程与烟火技 术专业建设, 三家单位为学生实践教学提供了很好的训练平台。2013年, 特种能源工程与烟火技术 专业更名为特种能源技术与工程专业。该专业2020年成为四川省一流本科专业建设点。

\section{3 结合新工科, “化学测量学与技术” 进入实践阶段}

2013年, 西南科技大学材料科学与工程学院与分析测试中心联合开办了应用化学 (仪器分析 方向)创新人才培养班, 经过数年的探索和实践, 积累了一些该专业方向建设与发展的成功经验, 为 2018 年参加郑兰茄院士主持的教育部首批 “新工科” 建设研究与实践项目 “基于化学的新工科专 业设置和建设方案研究” 奠定了基础。通过广泛调研、深入讨论, 教育部化学类专业教指委提出了 设置 “化学测量学与技术” 新专业的构想 ${ }^{[6,7]}$, 并对专业的培养定位、培养目标、毕业要求、教学内 容、课程体系以及师资队伍和教学条件建设等提出了具体建议。2021年 “化学测量学与技术” 被教 育部批准设置为新专业, 厦门大学成为全国第一个开办此新专业的学校。

\section{3 基于应用化学专业的学科、专业与课程一体化改革成效显著}

我校应用化学专业紧紧围绕立德树人根本任务, 依托共建与区域产学研联合办学模式, 将科研 教学协同育人融入学科、专业及课程一体化建设。围绕文化育人、学科育人、专业育人、课程育人 4大主题, 以 “三线精神” “两弹精神” “西南科大精神” 为引领, 以化学学科文化、化学学科思 想 ${ }^{[8]}$ 和化学学科核心素养 ${ }^{[9]}$ 培育为基础, 以教师队伍、专业知识、培养方案、平台、应用化学专业导 论、专业课思政建设为重点, 融合爱国主义教育基地、西南科大发展史、化学发展史、诺贝尔化学 奖等教育资源; 突出专业教育的元素观、微粒观、结构观、物质观、变化观、平衡观、实证观、绿 色观、宏观辨识与微观探析、变化观念与平衡思想、证据推理与模型认知理念; 强化科学探究与创 新意识、科学态度与社会责任; 推进导师加团队、通识类知识、学科基础知识、专业理论知识、实 验基本内容、实践性教学环节、专业课程体系建设; 打造学科平台、教学平台、创新创业平台; 最 终构建了适应新时代学科、专业与课程一体化的三全育人生态系统, 推进复合创新型人才培养, 取得 积极成效。

\section{1 导师加团队和基层教学组织建设成效显著}

绵阳是国家国防科技及军民融合产业的重要基地, 是孕育和生动体现 “三线精神” (艰苦创业、 无私奉献、团结协作、勇于创新)和 “两弹精神” (热爱祖国、无私奉献, 自力更生、艰苦奋斗, 大力 协同、勇于登攀)的溯源地。学院挖掘区域特色优势, 与中国工程物理研究院、中国空气动力研究与 发展中心及长虹集团等董事单位开展共建。与中国工程物理研究院化工材料研究所联合建成应用化 学和分析化学硕士点, 带动了学院化学学科的发展。将大量科研实践经验丰富的董事单位科研人员 
聘为本科生团队导师, 助力科研教学协同育人, 同时将学科教师全纳入本科生导师队伍, 构建了学 科、专业与课程一体化的师资队伍。

坚持引进与培养并举, 实施 “学术院长” “客座教授” “学术带头人” “特聘学科带头人” “产 业教授” “创业导师” 等一系列人才引进计划以及 “龙山学术人才计划” “中青年教师教学能力提 升计划” “导师实践指导能力提升计划” 等政策与措施, 加大师资队伍建设力度。紧密围绕人才培 养工作, 设立院、系、教研室、实验中心、课程组等单位, 明确各基层组织的工作职责。建立院级 教学督导、同行听课评价、青年教师助教、教学信息反馈等规范的教师能力培养体系及管理制度。 采取教改积分、课程教学质量评价、教学竞赛等激励政策, 引导教师开展教育教学研讨与改革, 提 升教学水平。引进产业教授 5 人, 培养 “新世纪百千万人才工程” 国家级人选、省学术和技术带头人 及后备人选、教学名师等省级以上高层次人才 60 多人次, 建设国家级化学实验教学团队和国防及省 级科研团队 6 个。近五年, 教师共承担项目 200 余项, 到校科研经费 1.7 亿余元; 获国家、省部级奖励 10 余项; 发表SCI论文 455 篇, 授权专利 67 项, 科研成果转化实现经济效益近 13 亿元。出版/编写教材 18 部，获省级教学成果奖 5 项。承担省部级及以上教改项目 14 项，发表教改论文 60 余篇。

\section{2 构建了学科、专业与课程一体化的优势资源共享平台}

多年来, 学院充分发挥区域产学研联合办学优势, 依托董事单位的资源优势, 建设了四川省化 学与分析测试中心、实验教学中心、国家大学科技园和工程训练中心、环境友好能源材料国家重点 实验室、生物质材料教育部工程中心等国家级和省部级平台。与中国工程物理研究院、四川美丰化 工股份有限公司、绵阳丰谷股份公司、新疆屯河集团股份公司等20余家企事业单位签订产学研全面 合作协议, 建有 20 多个校外实习实践基地, 实现资源共享。每年利用建成的开放创新实验平台, 自 主参与实验学习的学生人数约 2000 人次; 平均每年参与教师科研项目的学生人数约 400 人。作为校级 “材科杯” 课外科技活动和 “化学综合设计实验大赛” 的主赛场, 每年有 500 余人参加相关科技竞赛 活动。学院还建设了 “挑战杯” 培训基地, 每届参赛的学生都超过 100 人次。

\section{3 构建了学科、专业与课程一体化的课程体系}

学院将学科发展、“新工科” 思想融入专业课程和教材中, 将化学学科思想与核心素养融入应 用化学课程教学, 将 “三线精神” “两弹一星精神” 等爱国主义教育、国防军工教育内容融入应用 化学课程教学, 强化学生使命担当。在教学中深度融入 Outcome Based Education (OBE)教育理念, 按 照工程教育认证要求和化学类专业教学质量国家标准, 开设计算机、计算机在化学化工中的应用、 程序设计基础(Python)、化工仪表及自动化等课程, 以适应国家新工科人才的培养。通过多年努力, 已建成化学综合设计实验、无机及分析化学、物理化学、普通化学等精品在线开放课程, 有国家、 省级和校级精品课程19门。《化学综合设计实验》《化工原理》《化工原理实验》《普通化学》《物 理化学实验》等教材已被国内 30 余所高校使用。《化学综合设计实验》还获得第九届中国石油和化 学工业优秀教材奖一等奖。

\section{4 专业创新能力教育初见成效}

\section{1 构建分类培养的特色化育人模式}

如何培养复合型、应用型、创新型人才是应用化学专业人才培养需要重点解决的问题。经过不 断的探索和实践, 本着服务地方经济、区域联合共建的原则, 学院初步建立了应用型人才、研究型 人才和工程技术人才分类培养的特色化培养新模式, 先后启动了 “卓越材料和化学工程师试点班”

“卓越应用化学工程师班” “应用化学专业(仪器分析方向)创新人才培养班”, 制定了独立的人才培 养方案, 设立了由分管教学院领导担任组长的 “卓越计划” 和 “拔尖创新人才培养计划” 领导小组, 使各部门、系室资源之间能够有机协同, 更好地服务于化学与材料类本科人才的培养。通过打造 “材 子家园” 品牌, 营造了浓郁的求学氛围和高雅的文化享受, 助力学生成人成才。 


\section{2 完善 “ $3+1$ ” 应用型人才培养}

通过前期探索, 我校应用化学专业采用了 “ $3+1$ ” 复合创新型人才培养模式, 即专业学生前 3 年 完成规定课程学习, 第4年进入企业开展实践教学环节。前 3 年, 给学生制定个性化培养方案, 由学 校教师和企业工程师共同完成理论和实践教学任务, 学科基础和专业特色课程实现理论与实际紧密 结合, 突出工程实践特色, 结合工程项目和课题对学生进行实践训练。第4年采用跟班、岗位锻炼等 方式学习本行业的生产与管理流程, 由企业方担任学生专业实践环节的指导与考评工作。同时根据 生产实际需要, 由学生、企业和学校三方协商确定学生毕业设计课题, 由校企双方共同承担对学生 毕业设计(论文)的指导, 实行 “双导师制”, 并组成答辩委员会对学生的毕业设计(论文)质量进行审 阅、质疑和评价。后期, 专业又建立了 “ $3+1+X$ ” 设计型人才培养模式, 将 $2-3$ 年的研究生阶段 学习与 “ $3+1$ ” 模式衔接, “3+1” 培养完成后, 学生可免试推荐进入研究生学习阶段 $(X)$, 第一年 在校内完成研究生阶段相关课程学习, 第二、三年进入企业开展工程实践项目的训练。研究生课程 设置以实际工程应用为导向, 教学内容要强调理论性与应用性课程的有机结合, 突出案例分析和工 程实践研究。校外导师全程参与研究生指导培养的各个环节。

为了保证 “ $3+1$ ” 的顺利实施, 我们建立了全程导师制。一年级有学院指定导师, 二年级时学 生、教师再进行双向选择, 学生选择适应自己兴趣的导师, 并在后三年接受所选导师指导, 完成毕 业论文。目前, 化学与材料类本科专业共有本科生导师 120 名。实践证明, 该制度有利于人才的因材 施教和分类培养。以本科生导师制为依托, 学院通过对相近研究方向的科研团队在教学上进行整合, 通过进入导师科研团队和组建学生创新团队等形式, 形成了层层递进的学生科研创新团队群, 使之 更加有利于学生自主创新能力的培养。

\section{3 学生培养质量大幅提升}

通过建立竞赛与课外科技活动常态化机制, 我校应用化学专业学生获得大学生创新创业训练计 划 10 余项, 本科生发表科研论文 70 多篇, 申请或获得授权专利 10 多项。此外, 学院组建了全国高分 子创新创业大赛、全国化工设计大赛、化学综合设计实验大赛等本科生科技活动教练团队, 指导学 生在相关竞赛中取得了优异成绩, 获得国家级奖励 10 余次, 其他奖励近 60 余次。毕业生受到社会的 普遍欢迎, 就业率达到 $95 \%$ 以上, 考研率逐年提高, 单班最高考研升学率接近 $70 \%$ 。多家企事业单位 在我院设立了专业奖学金。

\section{5 结语}

通过大胆探索与实践, 西南科技大学的应用化学专业建设取得明显成效, 人才培养质量不断提 升。这一成功表明, 挖掘区域特色优势, 开展共建与区域产学研联合办学, 将学科、专业与课程进 行一体化建设, 是西部、非中心城市地方高校建设国家一流专业的行之有效之路, 为高等学校专业 建设开辟新途径、提供新思路。

\section{参 考 文 献}

[1] 王强, 姜莉, 吴彪, 李雯, 张鹏. 黑龙江工程学院学报, 2019, №. 5, 65 .

[2] 周光礼. 教育研究, 2016, No. 5, 72.

[3] 王俊波, 肖正学. 中国高等教育, 2010, No. 23, 55 .

[4] 张庆, 张小乾. 西南科技大学学报: 哲学社会科学版, 2015, No. 3, 91 .

[5] 雷永林, 霍冀川, 叶旭. 宁夏大学学报(自然科学版), 2007, №. $28,31$.

[6] 张树永, 朱亚先, 霍冀川, 宋丽娟, 徐华龙, 郑兰苏. 大学化学, 2020, 35 (10), 6.

[7] 霍冀川, 张树永, 朱亚先, 李攻科, 杨屹, 李梦龙, 王玉枝, 郑兰䔉. 大学化学, 2020, 35 (10), 11.

[8] 傅兴春. 化学学科思想. 福州: 福建教育出版社, 2017: 3-7.

[9] 王否. 基于学生核心素养的化学学科能力研究. 北京: 北京师范大学出版社, 2017: 2-5. 